\title{
Tuberculosis or Sarcoidosis a Case Report
}

\author{
R. Lihiou1, H. Ben Brahim ${ }^{1 *}$, O. Harzallah ${ }^{2}$, A. Toumi ${ }^{1}$, Ch. Loussaïef ${ }^{1}$, M. Chakroun ${ }^{1}$ \\ ${ }^{1}$ Infectious diseases department- F.Bourguiba Hospital Monastir-Tunisia \\ ${ }^{2}$ Internal medicine department, F-Bourguiba Hospital Monastir-Tunisia
}

Corresponding Author: H. Ben Brahim, Infectious diseases department - F. Bourguiba Hospital Monastir-Tunisia

Received date: February 18, 2021; Accepted date: March 01, 2021; Published date: March 12, 2021

Citation: R. Lihiou, H. Ben Brahim, O. Harzallah, A. Toumi, Ch. Loussaïef. (2021) Tuberculosis or sarcoidosis. J. Archives of Medical Case Reports and Case Study. 4(1); DOI:10.31579/2692-9392/027

Copyright: (C) $2021 \mathrm{H}$. Ben Brahim, This is an open access article distributed under the Creative Commons Attribution License, which permits unrestricted use, distribution, and reproduction in any medium, provided the original work is properly cited.

\begin{abstract}
Distinguishing sarcoidosis from pulmonary tuberculosis can be a great challenge to physicians, especially in Tunisia where there is high prevalence of tuberculosis. Both tuberculosis and sarcoidosis are granulomatous diseases; however, necrosis is commun in tuberculosis and less commun in sarcoidosis. The presence of necrosis may lead to an excessive diagnosis of tuberculosis. We present the case of a 48 years old female in which nasosinusal tuberculosis was retained face to granulomatous inflammation with little fields of necrosis. The patient was treated for many months without healing. The diagnosis was revised when evolutive pulmonary lesions were observed while the patient was under well conducted anti-tubercular treatment. Sarcoidosis was in fine retained with good response to corticosteroid therapy.

Keywords: tuberculosis; sarcoidosis; granuloma
\end{abstract}

\section{Introduction}

Systemic granulomatosis are frequently encountered in internal medicine. The presence of necrosis inside, in an endemic country for tuberculosis like Tunisia may lead to retain the diagnosis of tuberculosis. Even though, other etiologies for systemic granulomatosis with necrosis may be mentioned, especially sarcoidosis witch have many similarities with tuberculosis. This case report, illustrate diagnostic difficulties between the two pathologies and discuss the possibility of association or causality relationship between them.

\section{Observation}

A 48 years old woman, with a history of right facial nerve palsy from 12 years old, had been in ORL department from 2003 for chronic nasal obstruction. In April 2008, nasal tuberculosis was diagnosed on nasal mucosa biopsy showing granulomatous inflammation with necrosis. In spite of no impregnation symptoms, anti-tubercular therapy (ATT) was instituted in June 2008, using the four routine antitubercular drugs: isoniazid $(\mathrm{H})$, rifampicin $(\mathrm{R})$, ethambutol $(\mathrm{E})$ and pyrazinamid $(\mathrm{Z})$. ATT was interrupted some days after by the patient because of digestive intolerance.

In August 2008, ATT was newly prescribed associating HRZE during 4 months and then HR for 10 months, with small improvement. A nasal biopsy practiced after six months showed granulomatous inflammation with little necrotic fields. Then, the patient was transferred to infectious diseases department for more exploration.

At admission, the patient was asymptomatic excepted nasal obstruction. The tuberculosis skin test was negatif, sputum and gastric fluid examination and cultures for acid fast bacilli were negative. On chest radiography, mediastinal enlargement was observed as well as interstitial lung disease in the lower part of the right lung (figure 1). 


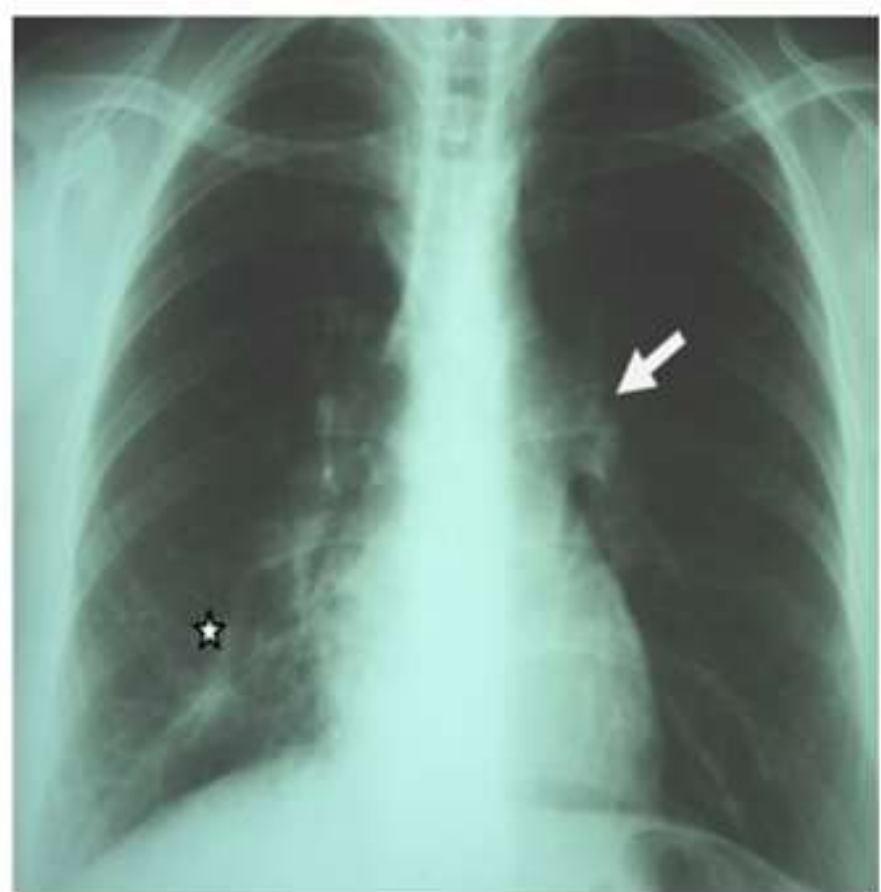

Figuare 1: mediastinal enlargement $(\quad$ ). Interstitial disease with irregular opacity ( $\quad$ ). (Marsh 2011)

Facial computed tomography scan showed: thickening of nasal cavity and right maxillary sinus mucosa (figure 2).

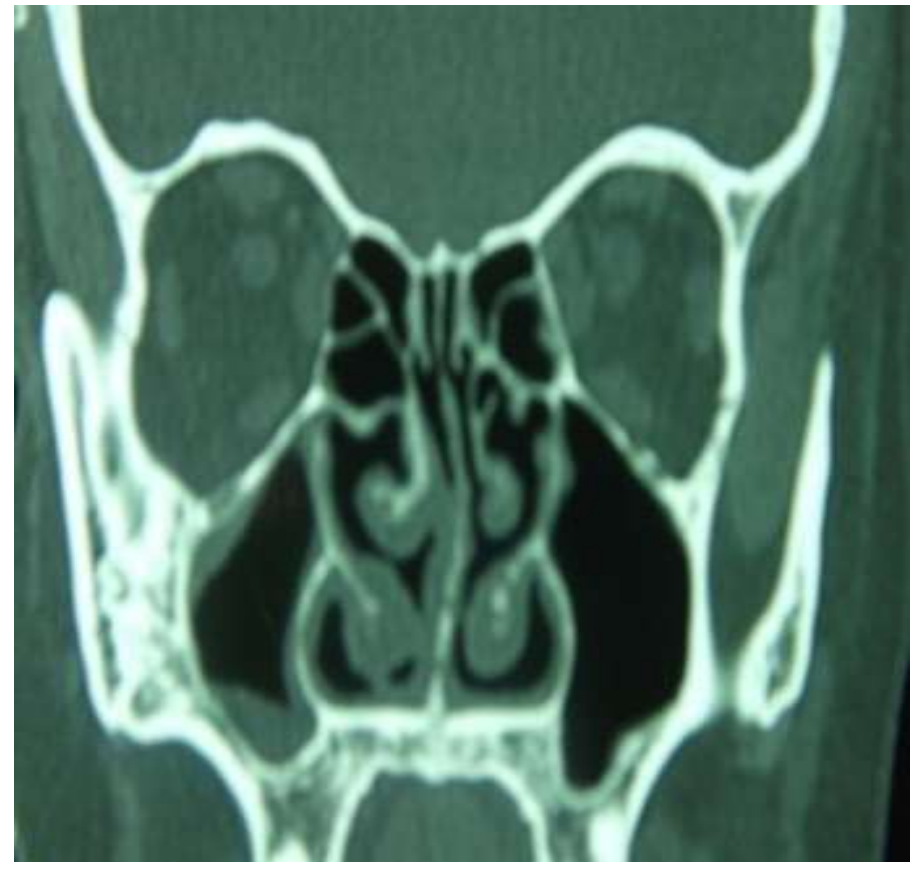

Figure 2: thickening of nasal cavity and right maxillary sinus mucosa. (Marsh 2011)

Thoraco-abdominal computed tomography scan showed mediastinal enlarged lymph nodes and alveolar condensation with central excavation, inside of ground-glass pattern in the lower right lung field (figure 3). 


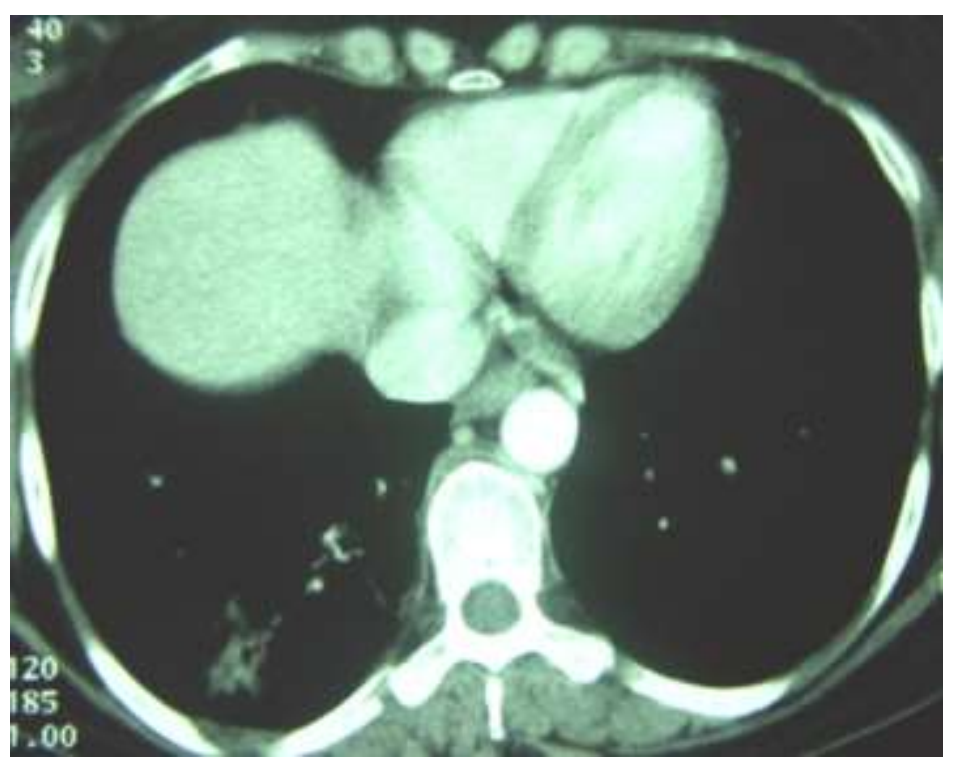

Figure 3: alveolar condensation with central excavation, inside of ground-glass pattern in the lower right lung field. (April 2011)

This presentation suggested evolutionary pulmonary tuberculosis occurring while the patient was under standard ATT with good tolerance and observance. Subsequently, multi-resistant mycobacterium tuberculosis or atypical mycobacterium infection were suspected and new ATT treatment protocol was prescribed associating Clarithromicin, Amikacin, Ethambutol, Rifampicin and Ofloxacin. In April 2011, non-granulomatous anterior uveitis occurred and had been controlled by corticotherapy and hypotonic treatment.
In November 2011, after seven months of ATT, nasal obstruction persists and the patient still free of respiratory symptoms. Computed tomography showed: stable naso-sinusal findings, no modification in mediastinal lymphadenomegalies size, worsening in lung damage; irregular alveolar condensations of the right basis, peripheral nodules and distortion of pulmonary architecture with bronchectasies (figure 4).

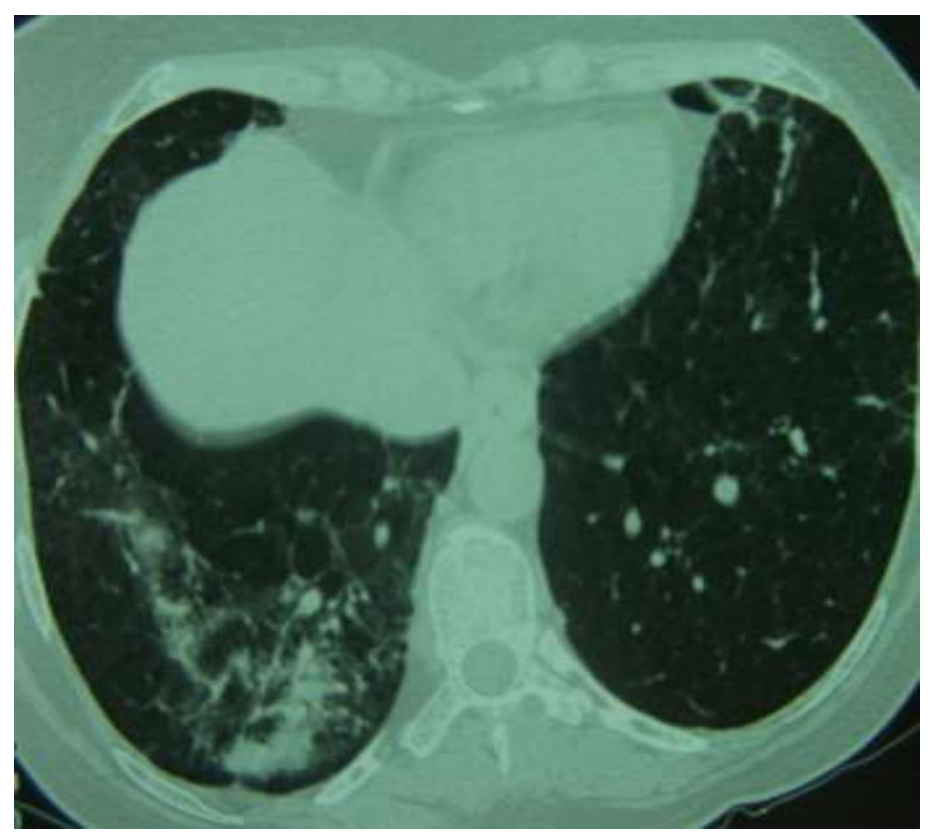

Figure 4: irregular alveolar condensations of the right basis. Distortion of pulmonary architecture with bronchectasies (November 2011)

These findings were very suggestive of pulmonary sarcoidosis isolated or added to tuberculosis.

In February 2012, the patient was hospitalized for exploration. She complained of moderate inflammatory joint pain, xerostomia, blurred vision and bilateral watering. She was free of fever, weight loss, dyspnea, cough, chest pain or hemopthysis.
Physical examination was normal excepted facial palsy. At standard biological tests: $\mathrm{Hb}=12.6 \mathrm{~g} / \mathrm{dl}, \mathrm{WBC}=4300 \mathrm{e} / \mathrm{mm} 3$ with lymphopenia $=$ $800 \mathrm{e} / \mathrm{mm} 3$, platelets $=260.000 \mathrm{e} / \mathrm{mm} 3, \mathrm{ESR}=15 \mathrm{~mm} / \mathrm{h}, \mathrm{CRP}=9 \mathrm{mg} / \mathrm{l}$, hypergammaglobulinemia $=15.5 \mathrm{~g} / \mathrm{l}$. proteinuria was positive $=0.2 \mathrm{~g} / 24 \mathrm{~h}$, urinalysis for bacteria was negative. Hepatic and renal tests were normal. Tuberculin skin test was anergic, mycobacterial tuberculosis bacilli were 
searched in sputum, gastric and bronchoalveolar lavage fluids with negative results.

Chest radiogram showed mediastinal enlargement with fibro-indurative changes in the area of the lower part of the right lung with traction and a focus of «round glass» pattern.

Since sarcoidosis was suspected, oriented tests were realized; calcium levels in plasma and urine were normal varying from 2.24 to $2.34 \mathrm{mmol} / \mathrm{l}$ and 0.06 to $0.07 \mathrm{mmol} / \mathrm{kg} / 24 \mathrm{~h}$ respectively. Angiotensin-converting enzyme (ACE) was elevated at $165 \mathrm{U} / \mathrm{l}(\mathrm{nl}=12-68 \mathrm{U} / \mathrm{l})$. Pulmonary function test was normal. In bronchoalveolar lavage (BAL), macrophages were predominant. No histological lesion was noted on salivary glands biopsy.

Ophthalmologic examination noted: ocular hypertension, sequels of bilateral anterior uveitis with large basis irido-cornean synechia. According to ophthalmologists, these findings suggest tuberculosis or sarcoidosis. Visual fields and color vision were normal.

AAN and ANCA search was negative.

Since sarcoidosis was suspected, corticosteroids therapy was initiated in Marsh 2012, justified by naso-sinusal localization. On the other hand, thoracic lesions since asymptomatic with no functional impact, did not justify corticotherapy. The patient was treated by prednisolone $0.5 \mathrm{mg} / \mathrm{kg}$ body weight/day, added to ATT witch was stopped after one month of association. Improvement in nasal obstruction was remarkable within 2 weeks. The patient is asymptomatic after six months of corticosteroid treatment.

\section{Discussion:}

Due to the marked clinico-radiological and histological similarity between tuberculosis and sarcoidosis, and the high prevalence of tuberculosis in our country, confusion may occur and the patients may receive unuseful repeated courses of anti-tubercular therapy [1].

Sarcoidosis is a multisystem disorder of unknown cause, characterized by non specific constitutional symptoms such as fever, weakness and weight loss. Commonly, the disease involves mediastinal lymph nodes and lungs (90\% of patients) but any other organ may be involved $[2,3,4]$.

The chest radiography is abnormal in 85 to $95 \%$ of cases. It commonly shows hilar and mediastinal lymphadenopathy. Other characteristic findings include interstitial lung disease, retractions and irregular opacities. Computed-tomography scan of the thorax shows thickening of bronchovascular bundles and perilymphatic distribution of nodules which represent the sarcoid granuloma [1,4]. At the stage of fibrosis: bronchial distortion, hilar retraction, diaphragmatic ascension and bronchectasies are noted. Perihilar masses rarely evolve toward the excavation. Aspects of ray honey, ground glass opacities and bubbles are rare [4].

The tuberculin anergy is present in $75 \%$ of cases. Generally there is no biological inflammatory syndrome. Hypergammaglobulinaemia is common. Lymphopenia, hypercalciuria, more rarely hypercalcemia may contribute to the diagnosis. The diagnostic value of ECA level is low [4]. At BAL, lymphocytes percentage over than $30 \%($ nle $=10-15 \%)$ increases the probability of sarcoidosis.

\section{References:}

1. Farheen Badar, Shah Farhan Azfar, Ibne Ahmad, Shagufta Yasmeen, Sanna Kirmani. Diagnostic Difficulties in Differentiating Sarcoidosis from Tuberculosis. Oman Medical Journal (2011) Vol. 26, No. 3: 210-211.
Histopathologically, sarcoidosis is characterized by the presence of noncaseating granuloma. Rarely, non-caseating necrosis may be noted on sarcoidosis granuloma, in this case little and fibrinoid [4, 5]. If the histopathology of the granuloma is atypical, such as the presence of necrosis, the clinical and radiological presentation must be considered [4].

Our case illustrates the diagnostic difficulties in separating tuberculosis from sarcoidosis. The presence of necrosis in side granuloma on biopsies made the diagnosis of tuberculosis the most plausible and ATT was instituted in spite of no other arguments for TBC. The presence of cavity formation, common in TBC and uncommon in sarcoidosis, strengthens this hypothesis. Repeated courses of ATT with whole duration of 25 months were instituted while lung damage continues to progress with new radiological findings more suggestive of sarcoidosis such us peripheral nodules and distortion of pulmonary architecture with bronchectasies. After oriented check-up, it has been

clear that the patient had many features of sarcoidosis, with usually negative reaction to tuberculin and no evidence of active tuberculosis. Mycobacterium tuberculosis was never isolated.

Recently, adding to the diagnostic difficulty, there are also some reports of coexistence of sarcoidosis and tuberculosis in the same patients [1].

Tuberculosis has been described as both preceding and coexisting with sarcoidosis, and as an opportunistic infection in patients with sarcoidosis who are on corticosteroids, which depress the cell-mediated immunity. Only few cases of TBC in patients with sarcoidosis have been reported in the world literature, and all of them had a course of corticosteroids or were immunosuppressed. Supriya. S and al relate a case of a patient, considered the unique in the literature, with sarcoidosis,

who had never taken corticosteroids and who develops tuberculosis [6].

Fite and al, in a study published in 2006, demonstrate that M. tuberculosis DNA was present in $9 / 23$ sarcoidosis biopsies (39\%), in 1/23 control patients $(4 \%)(\mathrm{p}=0.01)$, and in all tissue samples from 12 control patients with tuberculosis. These results do not demonstrate causality, although they may suggest a link between $M$. tuberculosis infection and sarcoidosis in some cases [7].

It is possible that a coincidental reactivation of tuberculosis with acute sarcoidosis occurred. However, in some cases there may be an etiological relationship between sarcoidosis and mycobacterial infection, and it is possible that clinical manifestations of sarcoidosis may have been a response to infection with M. tuberculosis [8].

\section{Conclusion:}

Clinical and radiological features of tuberculosis and sarcoidosis are quite similar. Exclusion of tuberculosis is important, particularly because corticosteroids form the mainstay of treatment for sarcoidosis. On the other hand, diagnosis of tuberculosis may be based on mycobacterium tuberculosis isolation or on caseating granuloma. If we have no bacteriological nor histological proof for tuberculosis or in case of no improvement after treatment test, this diagnosis may be quickly reconsidered.

2. Abdurrahman Tufana, Ortenca Rancib, Arzu Sungurc, Arzu Topelia, Ibrahım Haznedaroglud, Lutfi Cöplü. Concurrent presentations of the sarcoidosis, tuberculosis and lymphoma in a single patient. Respiratory Medicine (2006) 100, 951953.

3. Göksel KITER, Benan MÜSELLIM, Erdoğan ÇETINKAYA, Hatice TÜRKER, A. Esra KUNT 
UZASLAN, Esin YENTÜRK, Oğuz UZUN, Leyla SAĞLAM, Özlem ÖZDEMIR KUMBASAR, Gökhan ÇELIK, Gülfer OKUMUŞ, Peri Meram ARBAK, Gündeniz ALTIAY, Levent TABAK, Ayşın ŞAKAR COŞKUN, Serdar ERTURAN, Haluk TÜRKTAŞ, Enver YALNIZ, Atila AKKOÇLU, Candan ÖĞÜŞ,Ömer Tamer DOĞAN, Metin ÖZKAN, Serir ÖZKAN, Fatma Işıl UZEL, Gül ÖNGEN. Clinical presentations and diagnostic work-up in sarcoidosis : a series of Turkish cases (clinics and diagnosis of sarcoidosis). Tüberküloz ve Toraks Dergisi 2011; 59(3): 248258.

4. D. Valeyre, H. Nunes, F. Duperron, P. Soler, M. Kambouchner, M. Brauner. Sarcoïdose. EMC-Pneumologie 2 (2005) 147-164.

5. M. Pavic, E. Le Pape, P. Debourdeau, D. Rabar, L. Crevon, B. Colle, H. Rousset. Granulomatoses systémiques pseudosarcoïdosiques d'étiologie déterminée et non tuberculeuse. Étude de 67 observations. La Revue de médecine interne 29 (2008) 5-14.

6. Supriya Sarkar, Kaushik Saha, Chandra Shekhar Das. Isolated Tuberculous Liver Abscess in a Patient With Asymptomatic Stage I Sarcoidosis. Respir Care 2010;55(12):1751-1753.

7. E. Fité, MT. Fernández-Figueras, R. Prats, M. Vaquero, J. Morera. High Prevalence of Mycobacterium tuberculosis DNA in Biopsies from Sarcoidosis Patients from Catalonia, Spain. Respiration 2006;73:20-26.

8. M. Uddenfeldt, N. Stjemberg, R. Lundgren. Sarcoidosis or tuberculosis - a case report. Tubercle 63 (1982) 221-223.
This work is licensed under Creative Commons Attribution 4.0 License

To Submit Your Article Click Here: Submit Article

DOI:10.31579/2692-9392/027

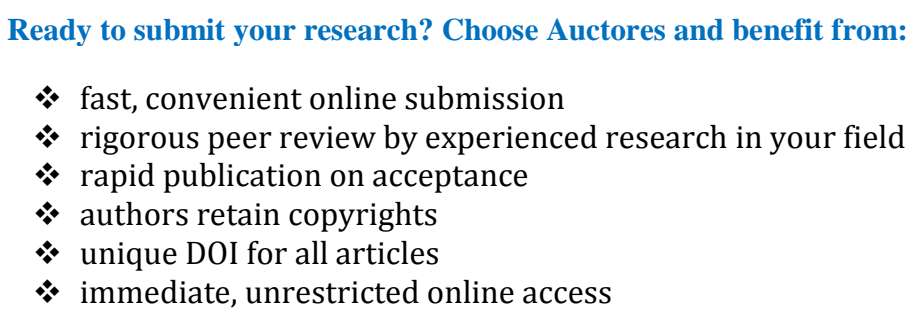

Ready to submit your research? Choose Auctores and benefit from:

* fast, convenient online submission

* rigorous peer review by experienced research in your field

* rapid publication on acceptance

* authors retain copyrights

* unique DOI for all articles

* immediate, unrestricted online access

At Auctores, research is always in progress.

Learn more www.auctoresonline.org/journals/archives-of-medical-casereports-and-case-study 